\title{
Erratum to: Concordance rates of Wilson's disease phenotype among siblings
}

\author{
Grzegorz Chabik • Tomasz Litwin • Anna Czlonkowska
}

Published online: 5 March 2014

(C) SSIEM and Springer Science+Business Media Dordrecht 2014

\section{Erratum to: J Inherit Metab Dis}

DOI 10.1007/s10545-013-9625-z

The Results section of this article contained errors. The third paragraph of the subsection headed "Genetic analysis" should have read as follows:

Aside from $\mathrm{H} 1069 \mathrm{Q}$, the most frequent missense mutations included T977M (c.2930C > T), T1220M (c.3659C $>$ T), S653Y (c.1958C >A), and G988R (c.2962G>C). Among severe mutations, the Q1351X (c.4051C>T), A1135fs (c.3402delC), D1047fs (c.3140delA), and M769fs (c.2304insC) were identified.

The authors apologize for any inconvenience caused.

The online version of the original article can be found at http://dx.doi.org/ 10.1007/s10545-013-9625-z.

G. Chabik · T. Litwin · A. Członkowska $(\bowtie)$

2nd Department of Neurology, Institute of Psychiatry and Neurology,

9 Sobieskiego Str., 02-957 Warsaw, Poland

e-mail: czlonkow@ipin.edu.pl 